Landslides (2018) 15:389-392 DOl 10.1007/s10346-017-0937-1 Received: 22 December 2017 Accepted: 25 December 2017 Published online: 5 February 2018 (c) Springer-Verlag GmbH Germany, part of Springer Nature 2018

\section{Kyoji Sassa \\ Zero Draft of the Kyoto 2020 Commitment for Global Promotion of Understanding and Reducing Landslide Disaster Risk}

The ISDR (International Strategy for Disaster Reduction)-ICL (International Consortium on Landslides) Sendai Partnerships 2015-2025 for global promotion of understanding and reducing landslide disaster risk was proposed by ICL to the working session "Underlying Risk Factors" at the World Conference on Disaster Risk Reduction (WCDRR) on 16 March 2015 in Sendai, Japan. It was adopted and signed by participating global stakeholders (Sassa 2015, Wahlström 2015). The progress made by the Sendai Partnerships from its foundation in 2015 to March 2017 was reported in Landslides Vol. 14 (3) (Sassa 2017a). One of the major achievements of this partnership was the organization of the Fourth World Landslide Forum on May 29-June 2, 2017 in Ljubljana, Slovenia (Mikos et al. 2017) and, within this forum was the high-level panel discussion: strengthening intergovernmental network and the International Programme on Landslides (IPL) for the ISDR-ICL Sendai Partnerships 2015-2025.

The Draft for the 2017 Ljubljana Declaration on landslide risk reduction and the concept of the Kyoto 2020 Commitment for global promotion of understanding and reducing landslide disaster risk were discussed on 30 May 2017 at the high-level panel discussion including the participants of WLF 4 (Sassa 2017b). The Declaration included the organization of the Fifth World Landslide Forum (WLF5) in Kyoto, Japan, in 2020 and the pursuit of the Kyoto 2020 Commitment process aiming at the launch of the commitment in WLF5. In the round table discussion on 31 May 2017 as a follow-up session to the high-level panel discussion, the 2017 Ljubljana Declaration, the plan of WLF5 (Sassa 2017d), and the concept note of the Kyoto 2020 Commitment for Global Promotion of Understanding and Reducing Landslide Disaster Risk were adopted (Sassa 2017b).

The basic concept of the Kyoto 2020 Commitment is to create a long-term, wider, and stronger framework for a global landslide risk reduction network (Sassa 2017b). The call for participating parties to the Kyoto 2020 Commitment was also endorsed as part of the concept (Sassa 2017c).

The 2017 ICL-IPL (International Programme on Landslides) Conference was organized at the UNESCO Headquarters in Paris, France, on 29 November to 1 December 2017. At that meeting, the Zero Draft of the Kyoto 2020 Commitment which was developed based on the concept of the Kyoto 2020 Commitment was presented and discussed. Following the discussion, key persons who were involved in the ISDR-ICL Sendai Partnerships further discussed and examined it and developed the Zero Draft of the Kyoto 2020 Commitment (Fig. 1).

ICL and IPL group will circulate the Zero Draft to all ICL-IPL colleagues and key partners of the Sendai Partnerships and invite their comments and contribution to complete the Draft of the Kyoto 2020 Commitment in order to reach a text which meets their acceptance and commitment. This step is expected to continue until the next ICL-IPL Conference to take place in Kyoto, Japan, on 2-4 December 2018.
The Draft will be shown to potential participating parties including the United Nations, international and national governmental organizations, non-governmental organizations, private organizations, and other entities which are willing to contribute to the ISDR-ICL Sendai Partnerships 2015-2025, the Sendai Framework for Disaster Risk Reduction 2015-2030, and the 2030 Agenda Sustainable Development Goals.

A fourth milestone will be approved in the Kyoto 2020 Commitment in November 2019 at the ICL-IPL meeting at the UNESCO, Headquarters, Paris, followed in turn by a call for participating parties to sign the Commitment. The final step will be the unanimous agreement on and launching of the Kyoto 2020 Commitment at the Fifth World Landslide Forum in Kyoto, Japan in November 2020.

The current Zero Draft of the Kyoto 2020 Commitment is as follows:

\section{Zero Draft}

Kyoto 2020 Commitment for Global Promotion of Understanding and Reducing Landslide Disaster Risk

To the ISDR-ICL Sendai Partnerships 2015-2025, the Sendai Framework for Disaster Risk Reduction 2015-2030 and the 2030 Agenda

Sustainable Development Goals

\section{Preamble}

Landslide disasters are caused by exposure to hazardous motions of soil and rock that threaten vulnerable human settlements in mountains, cities, coasts, and islands. An increase in the frequency and/or magnitude of heavy rainfall, and shifts in the location and periodicity of this rainfall due to changing climate may significantly intensify the risk of landslides in some landslide prone areas.

Developments in mountains and coastal areas, including construction of roads and railways, expansion of urban areas, including deforestation due to population growth and movement increase exposure to the hazards of landslides. Landslide disaster risk reduction is a globally important objective in all countries/ regions where people living in mountains and slopes are exposed to landslides.

The International Consortium on Landslides (ICL) proposed the Sendai Partnerships 2015-2025 for Global Promotion of Understanding and Reducing Landslide Disaster Risk in the Working Session "Underlying Risk Factors" during the 3rd World Conference on Disaster Risk Reduction (WCDRR) in Sendai, Japan. The Sendai Partnerships was adopted and signed by 17 United Nations, international and national stakeholders. Joint efforts thereafter have been made and resulted in the edition and publication of the open access full color book "ISDR-ICL Sendai Partnerships 2015-2025", Vol. 1 of the Fourth World Landslide Forum, the edition of "Landslide Dynamics: ISDR-ICL Landslide Interactive 


\begin{tabular}{|c|c|c|c|c|}
\hline $\begin{array}{l}\text { WLF4 } \\
\text { Ljubljana }\end{array}$ & $\begin{array}{l}\text { ICL-IPL Meeting } \\
\text { UNESCO, Paris }\end{array}$ & $\begin{array}{l}\text { ICL-IPL Meeting } \\
\text { KICC, Kyoto }\end{array}$ & $\begin{array}{l}\text { ICL-IPL Meeting } \\
\text { UNESCO, Paris }\end{array}$ & $\begin{array}{l}\text { WLF5 } \\
\text { KICC, Kyoto }\end{array}$ \\
\hline $5-6 / 2017$ & $11-12 / 2017$ & $12 / 2018$ & $11 / 2019$ & $11 / 2020$ \\
\hline $\begin{array}{l}\text { Concept note: } \\
\text { Call for } \\
\text { participating } \\
\text { parties }\end{array}$ & Zero Draft made & $\begin{array}{l}\text { Draft of Kyoto } \\
\text { Commitment } \\
\text { made and call } \\
\text { for parties and } \\
\text { comments }\end{array}$ & $\begin{array}{l}\text { Agreed the Kyoto } \\
\text { Commitment by parties } \\
\text { and request signature or } \\
\text { take signed document to } \\
\text { Kyoto }\end{array}$ & $\begin{array}{l}\text { Inaugural meeting } \\
\text { of Commitment } \\
\text { with the final } \\
\text { group of signature }\end{array}$ \\
\hline
\end{tabular}

Fig. 1 Timeline for the Kyoto 2020 Commitment Process

Teaching Tools", as well as the enhanced publication of the monthly full-color journal Landslides: Journal of the International Consortium on Landslides.

The landslide risk to human settlements in mountainous and coastal areas in many countries will likely continue to rise after the latter-half period of the Sendai Partnerships 2015-2025. In September 2015, the United Nations General Assembly adopted the 2030 Agenda for Sustainable Development and its 17 Sustainable Development Goals (SDG) including SDG 11 to 'Make cities and human settlements inclusive, safe, resilient and sustainable'. As a voluntary commitment to the 2030 Agenda, to the Sendai Framework for Disaster Risk Reduction 2015-2030 as well as to the ISDR-ICL Sendai Partnerships itself, participants in the Fourth World Landslide Forum considered and further endorsed the first outline of the Kyoto 2020 Commitment as a stable framework to mobilize in the medium and long term a global alliance which will accelerate and incentivize action for landslide disaster risk reduction.

The High-Level panel discussion on "Strengthening Intergovernmental Network and the International Programme on Landslides (IPL) for "ISDR-ICL SENDAI PARTNERSHIPS 2015-2025 for global promotion of understanding and reducing landslide disaster risk" was organized during the Fourth World Landslide Forum in Ljubljana on 30 May 2017. The panelists were from the signatory organizations of Sendai Partnerships (ICL, UNESCO, WMO, FAO, UNU, ICSU, WFEO, IUGS, IUGG, Cabinet Office of Japan, Italian Civil Protection, Global Risk Forum, Davos) and new signatory organizations (the Indonesian National Agency for Disaster Management, the Administration of the Republic of Slovenia for Civil Protection and Disaster Relief, Ministry of Natural Resources and Environment, Vietnam, IRDR Science Committee, EuroGeoSurveys) as well as experts in this field.

The outcome of this High-Level panel discussion was reviewed by the Round Table Discussion to promote the Sendai Partnerships and the participants approved the 2017 Ljubljana Declaration on Landslide Risk Reduction. The Declaration endorsed the plan for the organization of the Fifth World Landslide Forum in Kyoto, Japan in November 2020 and the preparation of the Kyoto 2020 Commitment of a global alliance which aims, in the medium and long term, to accelerate and incentivize action for landslide disaster risk reduction to 2025, 2030 and beyond.

The Kyoto 2020 Commitment is expected to reaffirm the following resolution of the Sendai Partnerships, acknowledging that:
- Landslide disasters are caused by exposure to hazardous motions of soil and rock that threaten vulnerable human settlements in mountains, cities, coasts, and islands.

- Climate change will intensify the risk of landslides in some landslide prone areas through an increase in the frequency and/or magnitude of heavy rainfall, and shifts in the location and periodicity of heavy rainfall.

- Developments in mountains and coastal areas, including construction of roads and railways and expansion of urban areas due to population shifts, increase exposure to hazards of landslides.

- Although they are not frequent, strong earthquakes have potential to trigger rapid and long runout landslides and liquefaction. Earthquake-induced coastal or submarine large-scale landslides or megaslides (with depths on the order of hundreds of meters to one thousand meters) in the ocean floor can trigger large tsunami waves. These hazardous motions of soil and water impacting on exposed and vulnerable population can result into very damaging effects.

- The combined effects of triggering factors, including rainfall, earthquakes, and volcanic eruptions, can lead to greater impacts through disastrous landslides such as lahars, debris flows, rock falls, and megaslides.

- Understanding landslide disaster risk requires a multi-hazard approach and a focus on social and institutional vulnerability. The study of social and institutional as well as physical vulnerability is needed to assess the extent and magnitude of landslide disasters and to guide formulation of effective policy responses.

- Human intervention can make a greater impact on exposure and vulnerability through, among other factors, land use and urban planning, building codes, risk assessments, early warning systems, legal and policy development, integrated research, insurance, and, above all, substantive educational and awareness-raising efforts by relevant stakeholders.

- The understanding of landslide disaster risk, including risk identification, vulnerability assessment, time prediction, and disaster assessment, using the most up-to-date and advanced knowledge, is a challenging task. The effectiveness of landslide disaster risk reduction measures depends on scientific and technological developments for understanding disaster risk (natural hazards or events and social vulnerability), political "buy-in", and on increased public awareness and education. 
- At a higher level, social and financial investment is vital for understanding and reducing landslide disaster risk, in particular social and institutional vulnerability through coordination of policies, planning, research, capacity development, and the production of publications and tools that are accessible, available free of charge and are easy to use for everyone in both developing and developed countries.

We agree on the following priority actions of Kyoto 2020 Commitment for Global Promotion of Understanding and Reducing Landslide Disaster Risk in research and capacity building, coupled with social and financial investment:

Action 1 Promote the development of people-centered early warning technology for landslides with increased precision and reliable prediction both in time and location, especially in a changing climate context.

Action 2 Advance hazard and vulnerability mapping, including vulnerability and risk assessment with increased precision, as well as reliability as part of multi-hazard risk identification and management.

Action 3 Improve the technologies for monitoring, testing, analyzing, simulating, and effective early warning for landslides suitable for specific regions considering natural, cultural and financial aspects.

Action 4 Apply the ISDR-ICL Landslide Interactive Teaching Tools to landslide prone areas and improve these with responses from users in developed and less developed countries.

Action 5 Promote open communication with society through integrated research, capacity building, knowledge transfer, awarenessraising, training, and educational activities to enable societies to develop effective policies and strategies for reducing landslide disaster risk, to strengthen their capacities for preventing hazards to develop into major disasters, and to enhance the effectiveness and efficiency of relief programs.

Action 6 Investigate the effect of climate change on large-scale landslides and debris flows and promote the development of effective prediction of localized rainfall to provide earlier warning and evacuation especially in developing countries

Action 7 Investigate the mechanism and dynamics of submarine landslides during earthquakes that may cause or enhance tsunamis, as well as develop and upgrade its hazard assessment and mitigation measures

Action 8 Promote geotechnical studies of catastrophic megaslides and develop their prediction and hazard assessment.

Action 9 Foster new initiatives to study research frontiers in understanding and reducing landslide disaster risk by promoting joint efforts by researchers, policy makers and funding agencies.

Action 10 Facilitate and encourage monitoring, reporting on, and assessing progress made, through the organization of progress report meetings at the regional and national level, to take place in respective countries, in order to show delivery and performance on progress made towards achieving the Kyoto 2020 commitment priority actions No.1-9. Participating parties and relevant stakeholders reporting on deliveries and achievements at these meetings are invited to report on this progress in the monthly full color journal "Landslides".
Commitments by all participating parties are called upon and periodically reviewed and updated at the Triennial World Landslide Forum.

Fundamental Coordinating Commitments by the International Consortium on Landslides (ICL) and the Global Promotion Committee of the International Programme on Landslides (IPL) and others to provide the common platform for the Kyoto 2020 Commitment include the following.

1. The Triennial Conference "World Landslide Forum" will be organized and the progress of Kyoto 2020 Commitment by all participating parties will be reported and examined for further development.

2. Landslides: Journal of International Consortium on Landslides will continue to be published monthly in full color and distributed to all participating parties.

3. Contribution fee and full color printing fee will continue to be waived to promote contribution from less developed countries and young researchers.

4. ICL provides that all parties of the Kyoto 2020 Commitment have the right to submit and publish news and reports of their activities in the "Landslides" journal. All parties will receive the print copy and digital access rights (tokens) to all issues of the journal (2002-present) as the common platform.

5. ICL will publish and update Landslide Dynamics: Landslide Interactive Teaching Tools (LITT) as a core activity for public education at each Forum. (The first LITT are edited and will be published including PPT for lessons and PDF for reference in digital format by the end of 2017 and in print copy by early 2018.)

6. ICL and IPL-GPC will organize the annual IPL symposium and publish a series of books with ISBN numbers together with Research, Administrative and Strategic Review meetings at UNESCO or elsewhere including the biennial Global Platform for Disaster Risk Reduction.

7. Other commitments by ICL and IPL groups will include:

- Landslide experts are called upon to gain trust and confidence from the local authorities and the communities facing the risk of landslides in order to effectively communicate the risk and urge local actions to help reduce the risk. Thus, ICL and IPL groups will promote a good dialogue at local levels throughout the activities of the Kyoto 2020 Commitment.

- To promote cooperation between policy makers, national government authorities working on landslide risk reduction and landslide scientists and engineers, a joint round table discussion between ICL members and high-level Ministerial members will be organized at each triennial Forum.

- Community safeguard policy for the countries/areas which are affected by rain-induced rapid and long-travel landslides, earthquake-induced megaslides as well as coastal and submarine landslides will be examined in specific sessions at each Forum.

- To identify, whenever possible and appropriate, focal points at the national/regional level in as many countries/regions as possible for engagement with the 
Kyoto 2020 Commitment and for ensuring contact and coordination with the Secretariat.

\section{A Call for joining the Commitment}

Competent global, regional, national, local institutions and entities participating in the Fifth World Landslide Forum are invited to support this initiative by joining and signing this Commitment through participation in clearly defined commitments for understanding and reducing landslide disaster risk. The potential parties are requested to make contact with the Secretariat of the host organization.

\section{Host Organization and Secretariat}

The International Consortium on Landslides (ICL) hosts the Kyoto 2020 Commitment as a voluntary commitment to the ISDRICL Sendai Partnerships 2015-2025, the Sendai Framework for Disaster Risk Reduction 2015-2030 and the 2030 Agenda Sustainable Development Goals. The ICL Secretariat in Kyoto, Japan, serves as the Secretariat of the Kyoto 2020 Commitment.

Signatories:

Signature

Position/Organization

Date

\section{ANNEX 1}

List of Commitments by participating parties will be attached in the ANNEX.

Note 1:

Commitments by ICL members and other parties (UN organizations, Governments and NGOs of Kyoto 2020 Commitment, and their joint group) will be attached.

Examples:

IPL activities, WCoE activities, ICL thematic, and regional activities can be one of commitments by ICL members.

Landslide and Hazard Assessment at UNESCO designated sites

(World Heritages, Geoparks, and Biosphere reserves) jointly planned by IRDR, UNESCO, and ICL.

Note 2:

The invited signatory organizations of the Kyoto 2020 Commitments will be as follows:

1. ICL supporting organizations (UNESCO, UNISDR, FAO, WMO, UNU, ICSU, WFEO, IUGS, and IUGG);
2. Sendai partnership signatory organizations (Governments of Japan, Italy, Croatia, Slovenia, Indonesia, Vietnam, IRDR, EuroGeosurveys, Science Council of Japan, Kyoto University, Global Risk Forum in addition to ICL supporting organizations);

3. All ICL member organizations (61), ICL supporters (10), and ICL associates (1) at present;

4. Other organizations which are willing to contribute to Kyoto 2020 Commitment and are ready to receive one volume of monthly Journal "Landslides" with its cost.

\section{Secretariat for the Kyoto 2020 Commitment}

Secretariat of the International Consortium on Landslides (ICL) 138-1 Tanaka-Asukai-cho, Sakyo-ku, Kyoto 606-8226, Japan

Tel: +81 (75) 723 0640, Fax: +81(75) 9500910

e-mail: secretariat@iclhq.org

IPL WEB: <http://iplhq.org/>, ICL WEB: <http://icl.iplhq.org/>, WLF5 WEB: <http://wlf5.iplhq.org/>

\section{References}

Mikos M, Yin Y, Sassa K (2017) The fourth world landslide forum, Ljubljana, 2017. Landslides 14(5):1843-1854. https://doi.org/10.1007/s10346-017-0889-5

Sassa K (2015) ISDR-ICL Sendai Partnerships 2015-2025 for global promotion of understanding and reducing landslide disaster risk. Landslides 12(4):631-640. https://doi.org/10.1007/s10346-015-0586-1

Sassa K (2017a) Progress of ISDR-ICL Sendai Partnerships 2015-2025 for global promotion of understanding and reducing landslide disaster risk. Landslides 14(3):783-788. https://doi.org/10.1007/s10346-017-0831-x

Sassa K (2017b) The 2017 Ljubljana Declaration on landslide risk reduction and the Kyoto 2020 Commitment for global promotion of understanding and reducing landslide disaster risk. Landslides 14(4):1289-1296. https://doi.org/10.1007/s10346-017-0857-0

Sassa K (2017c) Participants in the Fourth World Landslide Forum and call for ICL members, supporters, and associates. Landslides 14(5):1839-1842. https://doi.org/ 10.1007/s10346-017-0858-z

Sassa K (2017d) The Fifth World Landslide Forum-implementing and monitoring the ISDR-ICL Sendai Partnerships 2015-2025-timeline of the WLF5 organization process and call for session proposal. Landslides 14(5):1857-1859. https://doi.org/10.1007/ s10346-017-0859-y

Wahlström M (2015) Preface. Landslides 12(4):629. https://doi.org/10.1007/s10346-0150590-5

K. Sassa $(\square)$

International Consortium on Landslides (ICL),

Kyoto, Japan

Email: secretariat@iclhq.org 